\title{
Effect of the Etching Duration and Ultrasonic Cleaning on Microtensile Bond Strength Between Feldspathic Ceramic and Resin Cement
}

Leite, Fabiola Pessoa ; Ȯzcan, Mutlu ; Valandro, Luiz Felipe ; Cunha Moreira, Carlos Heitor ; Amaral, Regina ; Bottino, Marco Antonio ; Kimpara, Estevao Tomomitsu

DOI: https://doi.org/10.1080/00218464.2013.739024

Posted at the Zurich Open Repository and Archive, University of Zurich ZORA URL: https://doi.org/10.5167/uzh-100670

Journal Article

Accepted Version

Originally published at:

Leite, Fabiola Pessoa; Ȯzcan, Mutlu; Valandro, Luiz Felipe; Cunha Moreira, Carlos Heitor; Amaral, Regina; Bottino, Marco Antonio; Kimpara, Estevao Tomomitsu (2013). Effect of the Etching Duration and Ultrasonic Cleaning on Microtensile Bond Strength Between Feldspathic Ceramic and Resin Cement. Journal of Adhesion, 89(3):159173.

DOI: https://doi.org/10.1080/00218464.2013.739024 


\section{Original Paper}

\section{Effect of the Etching Time and the Ultrasonic Cleaning on Microtensile Bond Strength Between Feldspathic Ceramic and Resin Cement}

Running title: Resin bond strength to feldspathic ceramic

Fabíola Pessoa LEITE ${ }^{1}$, Mutlu OZCAN ${ }^{2}$, Luiz Felipe VALANDRO ${ }^{3}$, Regina AMARAL ${ }^{4}$, Marco Antonio BOTTINO ${ }^{5}$, Estevão Tomomitsu KIMPARA ${ }^{6}$

${ }^{1}$ DDS, PhD, Adjunct Professor, Federal University of Juiz de Fora, Faculty of Dentistry, Department of Restorative Dentistry.

${ }^{2}$ DMD, PhD, Professor University of Zürich, Head of Dental Materials Unit, Center for Dental and Oral Medicine, Clinic for Fixed and Removable Prosthodontics and Dental Materials Science.

${ }^{3}$ DDS, PhD, Associate Professor, MDS/PhD Graduate Oral Science Program, Prosthodontic Unit, Faculty of Odontology, Federal University of Santa Maria, Santa Maria, RS, Brazil.

${ }^{4}$ DDS, MS, Doctorate Student in Prosthodontic, São Jose dos Campos Dental School, São Paulo State University (UNESP), SP, Brazil.

${ }^{5}$ DDS, PhD, Professor, Department of Dental Materials and Prosthodontics, São Jose dos Campos Dental School, São Paulo State University (UNESP), São Jose dos Campos, SP, Brazil.

${ }^{6}$ DDS, PhD, Adjunct Professor, Department of Dental Materials and Prosthodontics, São Jose dos Campos Dental School, São Paulo State University (UNESP), São Jose dos Campos, SP, Brazil.

Key Words: acid etching, sonic cleaning, feldspathic ceramic, microtensile bond strength.

*CORRESPONDENCE AUTHOR:

Dr. Luiz Felipe Valandro, D.D.S, M.S.D., Ph.D., Associate Professor, Federal University of Santa Maria, Faculty of Dentistry $\mathrm{MSD} / \mathrm{PhD}$ Oral Science Graduate Program, Prosthodontics Unit

R. Marechal Floriano, 1184, 97015-372, Santa Maria, Brazil.

E-mail: Ifvalandro@hotmail.com

\section{Acknowledgements}

The authors thank Prof. Assist. Ivan Balducci for the statistical analysis review. The authors also thank the Vita Zahnfabrik (Bad Sackingen, Germany) for material support. This study is based on a Doctorate thesis submitted to the São José dos Campos Dental School, São Paulo State University (UNESP) (Brazil), as part of the requirements for the Doctor degree (Dr. Fabiola Leite). 


\section{Effect of the Etching Time and the Ultrasonic Cleaning on Microtensile Bond Strength Between Feldspathic Ceramic and Resin Cement}

\section{Abstract}

This study assessed the effect of different etching time of hydrofluoric acid and ultrasonic cleaning of the etched ceramic surface on the resin microtensile bond strength stability to a feldspathic ceramic. The research hypotheses investigated were: (1) different etching time does not affect the adhesion resistance; (2) ultrasonic cleaning improves the adhesion resistance. Forty-eight (48) blocks ceramic $(6 \times 6 \times 5 \mathrm{~mm})$ were obtained. The cementations surfaces were duplicated in resin composite. The six study groups ( $\mathrm{n}=8)$ were: G1: etching with 10\% HF (30s) + Silane; G2: 10\% HF (1min) + Silane; G3: 10\% HF (2min) + Silane; G4: 10\% HF (30s) + ultrasonic cleaning (4min) in distilled water + Silane; G5: 10\% HF (1min) + ultrasonic cleaning + Silane; G6: 10\% HF (2min) ultrasonic cleaning + Silane. The cemented blocks were sectioned and microbars for the microtensile test. The etching period did not create significant difference among the groups $(P=0.156)$. Significant influence of ultrasonic cleaning was observed $(P=$ 0.001) (Two-way ANOVA and Tukey's test, $p>0.05$ ). All the groups with ultrasonic cleaning had higher bond strength (range: 19.38 - 20.08 MPa) when compared to the correspondent group (range: $16.21-17.75 \mathrm{MPa}$ ).

Conclusions: The bond strength between feldspathic ceramic and resin cement is not affected by different etching times with HF; b) Ultrasonic cleaning increases the bond strength between ceramic surface and resin cement, regardless of the etching time.

\section{INTRODUCTION}


The concepts for use of metal-free fixed-partial-dentures made with feldspathic material (inlays, onlays, laminate veneers) changed by utilizing adhesives and minimal intervention approach, which allow preserve hard dental tissues greatly. But clinical durability of this kind of restorations depends on durable bonds at different interfaces concerned in the adhesive procedures [1,2]. Consequently a precise conditioning method of the inner surface of these restorations is a must. $[3,4,5]$

One type of dental ceramic is the feldspathic ceramic, which consists of a vitreous structure basically composed of two minerals, namely feldspar and quartz. The feldspar bonds to metallic oxides to form the vitreous phase of porcelain, whereas quartz composes the crystalline phase. More recently, a feldspathic ceramic classified as biphasic vitreous ceramic has been introduced in the market by the company Vita Zahnfabrik, called VM7. This ceramic material basically consists of Si: 19.6\%; Al: 4.9\%; K: 4.0\%; Na: 2.4\%; Ca: 0.7\%; C: $25.7 \%$ and O: $42.2 \%[3,4,5]$. This material is indicated for inlay or onlay partial restorations, laminate veneers and as veneering material on some high-ceramic frameworks.

The inner surface of ceramic restorations should be susceptible to surface treatments, to promote micromechanical retentions of resin agents on ceramic. may allow similar performance as the tooth structure.[4,5] The kind of ceramic surface treatment for adhesion proposal is defined according to the type of ceramic involved, as indicated by Valandro et al.[4], in 2005, who classified dental ceramics according to their sensitivity to hydrofluoric acid etching as: a) acid-sensitive - ceramics that suffer surface degradation by hydrofluoric acid (feldspathic, leucitic and lithium disilicate ceramics), giving rise to a topographic pattern that favors the micromechanical 
retention; b) acid-resistant - ceramics resistant to etching by hydrofluoric acid (glassinfiltrated alumina or alumina/zirconia ceramics, containing densely sinterized zirconia/yttrium and alumina, which are usually submitted to blasting to optimize adhesion)[4,5].

For acid-sensitive ceramics (kind of feldspar-based ceramic), some factors as type, concentration and time of hydrofluoric acid etching might have some influence on the resin bond strength, in function of the sensibility for dissolution by acid attack of glassy phase or leucite from these ceramics $[6,7,8,9]$. Thus, concentration and time of acid etching should be established according to the type of feldspathic ceramic, in order to improve the bond between with the bonding agent. Since these are critical factors for achievement of ideal bond strength $[7,8,10,11]$.

Acid etching with hydrofluoric acid on feldspathic ceramic significantly changes the surface morphology of ceramics, creating irregularities on the ceramic surface due to selective dissolution of the vitreous phase, which is represented by retentive micropores. The number and size of these micropores have been associated with an increase in bond strength and their presence enhances penetration of the bonding agen $[7,8,10,12], \mathrm{t}$.

Etchants as hydrofluoric acid react with silica present in porcelain and form acid precipitates (products of reaction of sodium fluorosilicate $(\mathrm{Na})$, potassium $(\mathrm{K})$, calcium (Ca) and aluminum (Al), which are located on the surface of micropores [13]. Their presence may damage the bond strength between ceramic and bonding agent and cause perhaps clinical failure of restorations [14]. Additional procedures may improve or aid in this bonding, e.g. elimination of excess acid and acid precipitates from the etched 
ceramic surface [15]. One such procedure is ultrasonic cleaning in distilled water, which seems to effectively remove this acid precipitate from ceramic restorations [13].

The comprehension of these factors displayed already has relevance, in view of the fact that the success and longevity of ceramic restorations are closely related to precementation surface treatment and to cementation itself $[1,2,7,8,16,17]$. Thus, the time of etching with hydrofluoric acid should be carefully followed, as well as cleaning of acid precipitates.

Hence, the objective of this study was to evaluate the impact of different time of hydrofluoric acid and ultrasonic cleaning of the etched ceramic surface on the resin microtensile bond strength stability to a feldspathic ceramic. The research hypotheses investigated were: (1) different etching time does not affect the adhesion; (2) ultrasonic cleaning improves the adhesion.

\section{MATERIALS AND METHODS}

Description of materials, trade names, and composition manufacturers are presented in Table 1.

\section{Production of ceramic blocks}

An acetate template measuring $8 \times 8 \times 6 \mathrm{~mm}$ was machined. 72 ceramic blocks (Vita VM7 Dentin 5M2, Vita Zahnfabrik, Bad Sackingen, Germany; Batch \# 7404) were prepared following the manufacturer's instructions. The ceramic bulk was inserted and packed into the template. The blocks were sintered in a furnace (Vacumat, Vita) using the specific program indicated by the manufacturer. After sintering shrinkage of the ceramic of nearly $20 \%$, the blocks measured approximately $6.4 \times 6.4 \times 4.8 \mathrm{~mm}$. 
The cementation surface $(6.4 \times 6.4 \mathrm{~mm})$ was flattened and polished in a machine (Labpol 8-12, Extec) using silicone carbide papers in a sequence of 600-, 800-, and 1200-grit (3M ESPE). Finally ceramic blocks were then ultrasonically cleaned with distilled water for 5 minutes (Vitasonic). Forty-eight ceramic blocks $(\mathrm{N}=48)$ were used for adhesion testing, 12 blocks for micro-morphological evaluations and 12 for EDS compositional analysis.

\section{Production of composite blocks}

Impressions were obtained from each ceramic block with putty addition silicone (Aquasil-Dentsply), with the bonding surface turned downward, so as it was impressed in the material, as well as the entire ceramic block. After polymerization of the impression material, each ceramic block was removed from the impression material. Composite resin (W3D Master, Wilcos, Petropolis, Brazil) was then inserted in the impression in 2-mm increments; each increment was light cured for 40 seconds (UltraLED-Ultradent) until complete filling of the impression, for achievement of a composite resin specimen for each ceramic specimen.

\section{Experimental design}

The 48 ceramic blocks were randomly divided into six groups $(n=8)$ (Table 2), according to the time of etching with $10 \%$ hydrofluoric acid, followed or not by the ultrasonic cleaning with distilled water for 4 minutes.

The adhesion surface of the ceramic blocks from the groups 1,2 and 3 were etched with $10 \%$ hydrofluoric acid for different times $(20 \mathrm{~s}, 1 \mathrm{~min}$, and $2 \mathrm{~min}$ respectively), followed by rinsing with air-water spray for 60 seconds, and air-drying for 30 seconds. The adhesion surface of the ceramic blocks from the groups 4,5 and 6 
received correspondingly the same acid etching described above, and additionally were, submitted to ultrasonic cleaning with distilled water for 4 minutes, and air-dried for 30 seconds.

\section{Cementation}

All the adhesion surfaces of the ceramic blocks were silanized by a MPS-based silane for $5 \mathrm{~min}$. Each ceramic block was bonded to the corresponding composite resin block with the resin cement RelyX ${ }^{\mathrm{TM}}$ ARC (3M/ESPE), prepared following the manufacturer's instructions and applied with a plastic spatula on the treated surface of each ceramic block. The assembly was placed on a surveyor adapted for cementation, with the cementation surface perpendicular to application of a $750-\mathrm{g}$ vertical static load $[4,18]$ employed throughout the procedure (10 minutes).

After positioning of the ceramic-cement-resin assembly, the excess cement was removed and light curing was performed on each adhesive interface for 40 seconds with a light curing unit (Ultra LED - Ultradent). The ceramic-cement-resin assemblies were stored in distilled water at $37^{\circ} \mathrm{C}$ for seven days until preparation of specimens.

\section{Production of non-trimmed beam samples}

Sectioning was performed with steel diamond discs ref 34570 (Microdont-Brazil) at low speed under water cooling, mounted on a handpiece (Kavo Ind. e Com. Ltda) connected to a modified mechanical lathe with calibration on the $\mathrm{x}$ and $\mathrm{y}$ axes, thus allowing sectioning in both directions $[4,7,17,18]$.

Initially, each ceramic-cement-composite resin assembly was fixated on a cylindrical metallic base with cyanoacrylate adhesive (Super Bonder, Loctite, Brazil). The metallic base was connected to a clamp in the sectioning machine. Each ceramic- 
cement-resin block should be perpendicular to the diamond disc to allow sectioning as regularly as possible, for achievement of homogeneous thickness of sections. The first section eliminated the end portion of the specimen $( \pm 0.5 \mathrm{~mm})$, which might have excess cement around the bonding interface, which in turn could directly influence the bond strength values. Thereafter, three sections were performed on the ceramic-cement-resin blocks, for achievement of sections with approximately $1 \mathrm{~mm}$ in thickness.

One of these sections was rotated in $90^{\circ}$ and once again fixated to the metallic base. The first section eliminated the end portion of the specimen $( \pm 0.5 \mathrm{~mm})$ for the same aforementioned reason. Further three sections with $\pm 1 \mathrm{~mm}$ in thickness were obtained. The same process was repeated for the other two sections, adding up to nine bar samples for each bonded ceramic-resin assembly, which presented the following characteristics: (a) beam shape; (b) non-trimmed square cross-section (1 $\mathrm{mm} \times 1 \mathrm{~mm}$ ); (c) bonded area of $\pm 1 \mathrm{~mm}^{2}$; (d) length of $\pm 8 \mathrm{~mm}[4,7,17,18,19,20]$.

\section{Microtensile bond strength testing}

For the microtensile testing, each bar specimen was fixated with cyanoacrylate adhesive (Super Bonder, Loctite) to an adapted caliper (apparatus), as perpendicular as possible to the force applied to avoid torsional stresses on the bonded area. Only the end portions of the specimens were used for fixation, so as the bonded area was located between the caliper tips. The apparatus-specimen assembly was placed in a universal testing machine (EMIC DL 1000) and submitted to tension $(v=1 \mathrm{~mm} / \mathrm{min}, 10-$ kgf load cell) until bonding failure.[4,7,17,18,19,20]

The interfacial cross-sectional area of all specimens was measured before testing with a digital caliper (Starret Indústria e Comércio Ltda) to 0.01-mm precision. 
Measurement of the area and the load value required for bonding failure allowed calculation of bond strength (MPa) according to the following equation: $R_{t}=F / A$, in which $R_{t}$ is the bond strength; $F$ is the force applied for adhesion failure; and $A$ is the adhered interfacial area.

After tensile testing, the surfaces of bar specimens were examined under a stereomicroscope (light microscope ZEISS MC 80 DX) at 50x magnification to establish the failure pattern at the ceramic/cement interface. Failure was then classified as adhesive, cohesive or mixed.

Representative pairs of tested specimen from each group were evaluated under scanning electron microscopy (SEM) (Jeol-JSM-T330A- Scanning Microscope-Japan) at $150 x$ magnification.

\section{Micro-morphologic and EDS analyses}

Additional ceramic blocks were conditioned as described in every groups and observed under SEM at $500 x$ to $2,000 x$ magnification to assess the topographic modifications caused by different ceramic conditioning regimens.

Additional conditioned ceramic blocks were analyzed by Energy Dispersive Spectrometry (EDS) to verify the chemical elements, which were presented on the ceramic surface. Mapping was performed per area to investigate the presence of precipitates of hydrofluoric acid on the ceramic surface.

\section{Statistical analysis}

Microtensile data were submitted to two-way ANOVA and post-hoc Tukey's test $(a l p h a=0.05)$. MINITAB (Minitab, version 14.12, 2004; State College, PA, USA), STATISTICA (StatSoft, version 5.5, 2000; Hamburg, Germany) and STATISTIX 
(Analytical Software, version 8.0, 2003; Tallahassee, FL, USA) were used to analyze the data. .

\section{RESULTS}

Two-way ANOVA (Table 3) revealed that the "time of acid etching" factor had no influenced on the bond strength results $(p=0.156)$, requiring acceptance of the research hypothesis 1 . In the other side, the "ultrasonic cleaning" factor significantly influenced the adhesion results $(p=0.001)$, therefore requiring rejection of the research hypothesis 2. The interaction between them was not significant $(p<0.0001)$.

Tukey's test (Table 4) indicated that: (1) considering only the ultrasonic cleaning factor, independent of time of conditioning, the sonic cleaning after acid etching improved the resin bond strength significantly. Comparing the groups submitted to the cleaning or not, keeping constant the times of acid conditioning, it notes the groups which were cleaned after etching had higher bond strength $(19.5 \pm 2.5 \mathrm{MPa})$ when compared to correspondent group without cleaning $(16.2 \pm 3.2 \mathrm{MPa})$. Besides, for all times of acid conditioning of the surface ceramic, the surface cleaning promoted improvement of microtensile bond strength (Table 4).

SEM analysis of fractured specimens revealed that all fractures occurred within the adhesion interface zone. The interfacial area is defined as the region in which the adhesive interacts with the two substrates, promoting bonding. The bonding area in this study comprised the following: a) interfacial region between adhesive and resin cement, in which there is molecular interaction and chemical bond between the two materials; b) resin cement; c) interfacial region between resin cement and ceramics, including the 
region of surface treatment with $10 \%$ hydrofluoric acid, in which there is micromechanical and chemical bonding.

Light microscopy and SEM analyses of failure pattern of specimens submitted to tensile strength testing revealed $100 \%$ of failures occurred at adhesive zone.

Figure 1 presents micrographs [500x (A) and 2,000x (B), respectively] of ceramic surfaces after treatment with $10 \%$ hydrofluoric acid at different etching times, which were not ultrasonically cleaned. These images demonstrate formation of three types of morphological changes: pores, grooves and deposition of precipitates resulting from etching of ceramic surfaces by hydrofluoric acid on all specimens. The micropores and grooves were quantitatively increased with the increase in etching time. There was also increase in the size of micropores, which were larger with the increase in etching time.

Figure 2 presents micrographs [500x (A) and 2,000x (B), respectively] of ceramic surfaces after treatment with $10 \%$ hydrofluoric acid at different etching times, and after ultrasonic cleaning. It demonstrates that the sonic cleaning is capable of removing acid precipitates, which it appears have cleaned more efficiently the opening of micropores and grooves.

Chemical elemental analysis (EDS) (Figure 3) revealed the presence of elements as $\mathrm{Si}, \mathrm{Al}, \mathrm{Na}, \mathrm{K}$ and $\mathrm{O}$, which characterize the microstructure of a vitreous ceramic, which contains a network of silica $\left(\mathrm{SiO}_{2}\right)$ and potassium $\left(\mathrm{K}_{2} \mathrm{O} . \mathrm{Al}_{2} \mathrm{O}_{3} \cdot 6 \mathrm{SiO}_{2}\right)$ or sodium $\left(\mathrm{Na}_{2} \mathrm{O} \cdot \mathrm{Al}_{2} \mathrm{O}_{3} \cdot 6 \mathrm{SiO}_{2}\right)$ feldspar, or both. (Figure $\left.3 \mathrm{~A}\right)$

The spectra of specimens etched by hydrofluoric acid revealed the presence of chemical element fluorine, which is characteristic of acid precipitate (reaction products of $\mathrm{Na}, \mathrm{K}$, calcium (Ca) and Al fluorosilicate) (Figure $3 \mathrm{~B}-\mathrm{C}-\mathrm{D}$ ). On contrary, EDS 
analysis of the specimens acid-etched and submitted to the sonic cleaning showed absence of fluorine element, which may indicate that the cleaning removed it out from ceramic surface. (Figure 3 E-F-G)

\section{DISCUSSION}

Hydrofluoric acid followed by silanization is the surface treatment most frequently employed for feldspathic ceramics $[14,16,22,23,24,25]$. The effect of etching with hydrofluoric acid may be explained by the chemical nature of the etching process. Hydrofluoric acid preferably reacts with the silica present in the ceramic microstructure, forming hexafluorosilicates. As a result of this reaction, the ceramic surface becomes porous and irregular, which increases the surface area and enhances penetration of the bonding agent into microretentions on the acid-etched ceramic surface [13].

The literature presents some studies, as those conducted by Tylca \& Stewart [6], Chen et al.[25], Chen et al.[26], and Shimada et al.[27], which address the effect of different etching times with hydrofluoric acid on the bond between bonding agent and the surface of feldspathic ceramics. The ceramic VM7 (Vita) is a type of feldspathic ceramic indicated for fabrication of indirect restorations and to cover In-Ceram frameworks. However, this ceramic was recently introduced in the market and thus no information was available on its adequate etching time. Therefore, the first objective of this study was to characterize the etching time for this ceramic. The etching times employed were based on the literature $[19,25,26,27]$.

The results observed in Table 3 reveal no statistically significant influence $(p=$ 0.156) from the etching time with hydrofluoric acid on the bond strength results. This 
does not corroborate the results of Chen et al.[26], who observed that the increase in etching time also led to an increase in bond strength. However, this study used a different ceramic. According to Della Bona et al. [23], the ceramic microstructure and ceramic composition control the development of mechanical microretentions produced by hydrofluoric acid etching; this may have influenced the discordant results.

Ultrasonic cleaning of the etched ceramic to remove the precipitates caused by hydrofluoric acid from the ceramic surface with distilled water is a previous procedure for cementation and was also analyzed in this study. According to Canay et al.[13], these acid precipitates are insoluble fluorosilicate salts that remain on the surface of micropores, thus can possibly reduce the bond strength between cement and ceramic. Ultrasonic cleaning with distilled water was performed for 4 minutes, as suggested by Canay et al.[13].

Table 3 reveal that the effect of ultrasonic cleaning of acid precipitates with distilled water was statistically significant $(p=0.001)$. The Table 4 displayed the mean bond strength values achieved in the ultrasonic cleaning groups were higher than the respective groups without cleaning procedure, regardless of the etching time. This may have occurred because ultrasonic cleaning can have removed the acid precipitates, consequently the resin cement can interact more efficiently with the etched ceramic surface, in terms of micro-mechanical retention and chemical reaction.

The bond strength values obtained by ultrasonic cleaning could not be compared to findings of other authors, since no studies were found in the literature addressing the same subject. 
Utilization of silane is very important for adhesive cementation, as mentioned by Della Bona et al.[20] and Jardel et al.[22], since it is an organofunctional molecule that promotes chemical bonding between inorganic substrate, herein represented by silicon in the vitreous matrix of feldspathic ceramic Vita VM7, and organic polymers as HEMA, which is found in the resin cement Rely X. According to Canay et al.[13], the application of silane on the hydrofluoric acid-etched ceramic surface may cause dissociation of fluorosilicate salts. This occurs by hydrolysis and absorption of silane on the etched ceramic surface. Another important factor is the capacity of silane to promote better surface wettability, increasing the contact and infiltration of bonding agent into porosities created on the ceramic surface by hydrofluoric acid etching[29].

The analyses of failures of the beam specimens submitted to the microtensile testing displayed that the all the failure occurred at adhesive zone. The adhesive zone represents the region of ceramic etched by acid, the interface, and the resin cement next closed to the interface. These findings corroborated with the information from the literature, which state that the percentage of failures at adhesive zone is higher in microtensile test; on the other hand, other bond tests with different geometries promote higher frequency of cohesive fractures of the substrates [20,23,30-37].

According to the findings from this current investigation, it may be stated that different etching times with hydrofluoric acid appear have no influence on resin bond strength to tested ceramic, even thought the etching time of 20 sec saves time and thus it could be recommended for this ceramic, from the clinical time-consuming point of view. On the other hand, the ultrasonic cleaning of the etched ceramic surface appear improve the bond strength, regardless of the etching time with hydrofluoric acid. Thus, 
this procedure could be recommended before cementation. Further investigation in long-term aging conditions should be conducted to better statement of adhesive performance in function of the studied circumstances.

\section{CONCLUSIONS}

1- The different acid etching times (20 sec, $1 \mathrm{~min}, 2 \mathrm{~min}$ ) promoted similar resin bond strength to the feldspathic ceramic.

2- The ultrasonic cleaning of the etched ceramic surface promoted significantly improvement of the adhesion between resin cement and ceramic.

\section{REFERENCES}

1. Fradeani, M., and Redemagni, M., Quintessence Int. 33, 503-510 (2002).

2. Hayashi, M., Tsuchitani, Y., Kawamura, Y., Miura, M., Takeshige, F., and Ebisu, S., Oper. Dent. 25, 473-481 (2000).

3. Borges, G. A., Sophr, A. M., de Goes, M. F., Sobrinho, L. C., and Chan, D.C., J. Prosthet. Dent. 89, 479-488 (2003).

4. Valandro, L. F., Della-Bona, A., and Bottino, M. A., J. Prosthet. Dent. 93, 253-259 (2005).

5. Ozcan, M., and Vallitu, P. K., Dent. Mater. 19, 725-731 (2003).

6. Tylca, D. F., and Stewart G. P., J. Prosthet. Dent. 72:121-127 (1994).

7. Amaral, R., Ozcan, M., Bottino, M. A., Valandro, L. F., J. Adhes. Dent. Nov 8. doi: 10.3290/j.jad.a19815 (2010).

8. Naves, L. Z., Soares, C. J., Moraes, R. R., Gonçalves, L. S., Sinhoreti, M. A., and CorrerSobrinho, L., Oper. Dent. 35, 420-427 (2010).

9. Belli, R., Guimarães, J. C., Filho, A. M., and Vieira, L. C., J. Adhes. Dent. 12, 295-303 (2010). 
10. Addison, O., Marquis, P. M., and Fleming, G. J., Dent Mater. 23, 461-468 (2007).

11. Simonsen, R. J., and Calamia, J. R., J. Dent. Res. 62, 297 (1983).

12. Stangel, I., Nathanson, D., and Hsu, C. S., J. Dent. Res. 66, 1460-1465 (1987).

13. Canay, S., Hersek, N., and Ertan, A., J. Oral. Rehabil. 28, 95-101 (2001).

14. Phoenix, R. D., and Shen, C., Int. J. Prosthodont. 8, 187-194 (1995).

15. Magne, P., Belser, U. Berlin: Quintessence (2003).

16. Spohr, A. M., Sobrinho, L. C., Consani, S., Sinhoreti, M.A., and Knowles, J. C., Int. J. Prothodont.16, 277-282 (2003).

17. Brentel, A., Özcan, M., Valandro, L. F., Amaral, R., Alarça, L. G., and Bottino, M. A., Dent. Mater. 23, 1323-1331 (2007).

18. Leite, F. P. P., Andreatta Filho, O. D., Valandro, L. F., Lopes, A. G., and Kimpara, E. T., Braz. Oral. Sci. 8, 6-14 (2005).

19. Shono, Y., Ogawa, T., Terashita, M., Carvalho, R. M., Pashley, E. L., and Pashley, D. H., J. Dent. Res. 78, 699-705 (1999).

20. Della-Bona, A., Anusavice, K. J., and Shen, C., J. Adhes. Dent. 26, 305-313 (2000).

21. Bianchi, B., Sao Paulo: Sao Paulo University (Doctorate Thesis), 112 (1999).

22. Jardel, V., Degrange, M., Picard, B., and Derrien, G., Int. J. Prosthodont. 12, 59-64 (1999).

23. Della-Bona, A., Anusavice, K. J., and Hood, J. A. A., Int. J. Prosthodont. 15, 248-253 (2002).

24. Saraçoglu, A., Cura, C., and Götert, H. S., J. Oral. Rehabil. 31, 790-797 (2004)

25. Chen, J. H., Matsumura, H., and Atsuta, M., J. Dent. 28, 53-58 (1998).

26. Chen, J. H., Matsumura, H., and Atsuta, M., Oper. Dent. 23, 250-257 (1998).

27. Shimada, Y., Yamaguchi, S., and Tagami, J., Dent. Mater. 18, 330-338 (2002).

28. Aida, M., Hayakawa, T., and Mizukawa, K., J. Prosthet. Dent. 73, 464-470 (1995).

29. Söderholm, K. M., and Reetz, E. A., Gen. Dent. 44, 296-302 (1996). 
30. Sano, H., Shono, T., Sonoda, H., Takatsu, T., Ciucchi, B., Carvalho, R., and Pashley, D. H., Dent. Mater. 10, 236-240 (1994).

31. Van Noort, R., Noroozi, S., Howard, I. C., and Cardew, G., J. Dent. 12, 61-67 (1989).

32. Versluis, A., Tantbirojn, D., and Douglas, W. H., J. Dent. Res. 76, 1298-1307 (1997).

33. Kitasako, Y., Burrow, M. F., Nikaido, T., Harada, N., Inokoshi, S., Yamada, T., and Takatsu T., Dent. Mater. 11, 298-304 (1995).

34. Phrukkanon, S., Burrow, M. F., and Tyas, M. J., Dent. Mater. 14, 120-128 (1998).

35. Phrukkanon, S., Burrow, M. F., and Tyas, M. J., Dent. Mater. 14, 212-221 (1998).

36. Shono, Y., Terashita, M., Pashley, E. L., Brewer, P. D., and Pashley, D. H., Dent. Mater. 13, 290-296 (1997).

37. Shono, Y., Terashita, M., Shimada, J., Kozono, Y., Carvalho, R. M., Russel, C. M., and Pashley, D. H., J. Adhes. Dent. $1211-218$ (1999). 


\section{FIGURES}

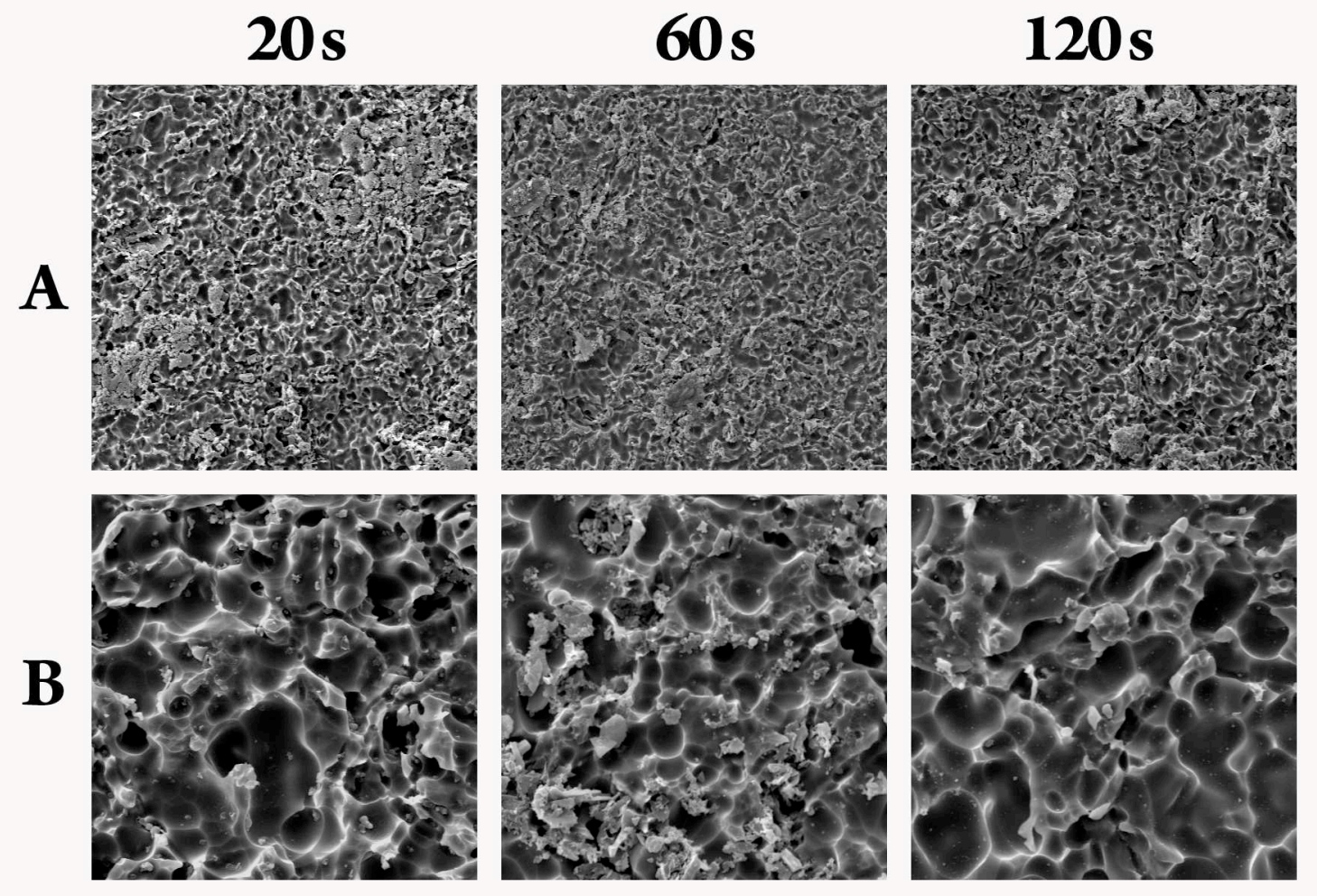

Figure 1. Micrographs (A- 500x, and B- 2,000x) of the acid-etched ceramic surfaces at different etching times ( $20 \mathrm{~s}, 1 \mathrm{~min}, 2 \mathrm{~min}$, from left to right respectively), without sonic cleaning. 


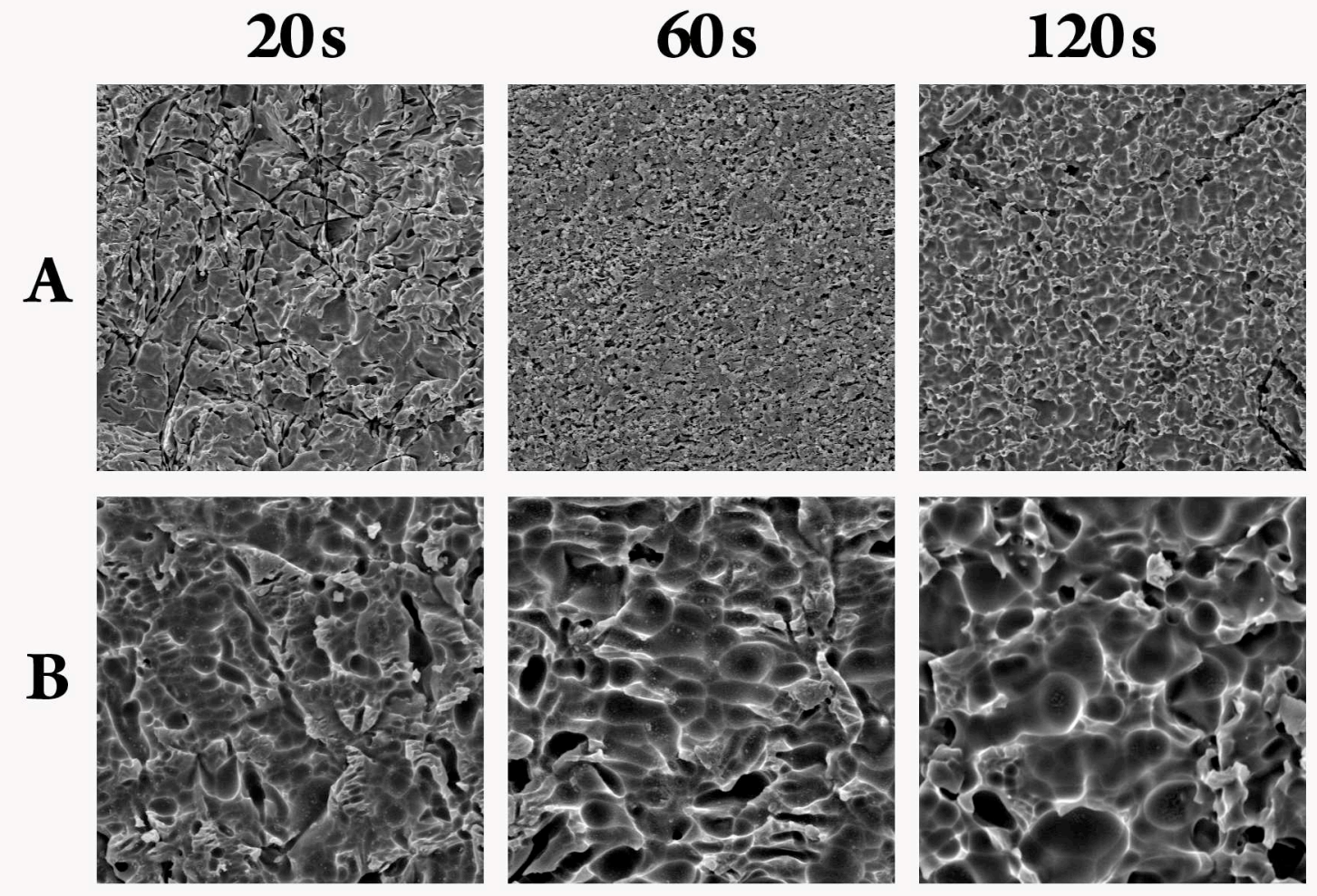

Figure 2. Micrographs (A- 500x, and B- 2,000x) of the acid-etched ceramic surfaces at different etching times ( $20 \mathrm{~s}, 1 \mathrm{~min}, 2 \mathrm{~min}$, from left to right respectively), and submitted to sonic cleaning. 

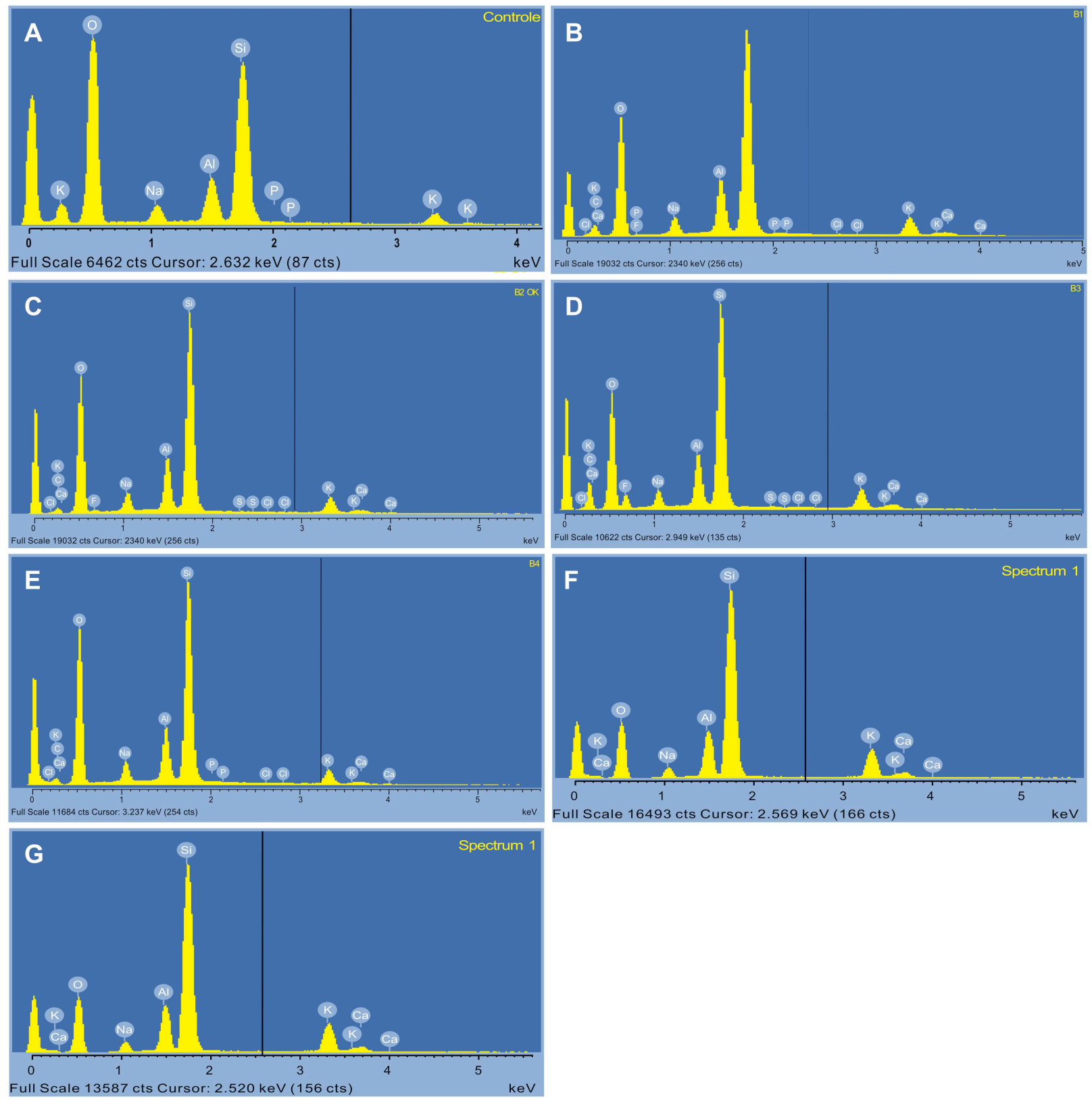

Figure 3. Spectra of the EDS analysis of the ceramic surface conditioned by different modes compared to no-conditioned surface: A- no-etched surface; B, C and D: ceramic surface etched with hydrofluoric acid for $20 \mathrm{sec}, 1 \mathrm{~min}$, and $2 \mathrm{~min}$ respectively (it notes the $\mathrm{F}$ element has been detected); E, F and G: ceramic surface etched with hydrofluoric acid for $20 \mathrm{sec}, 1 \mathrm{~min}$, and $2 \mathrm{~min}$ respectively, associated to the sonic cleaning (it notes the $\mathrm{F}$ element has not been detected). 


\section{TABLES}

Table 1. Materials used in this study.

\begin{tabular}{l|l|l}
\hline Trade name & Manufacturer & Composition \\
\hline VITA VM ${ }^{\circledR 7}$ & $\begin{array}{l}\text { VITA Zahnfabrik, Bad } \\
\text { Säckingen, Germany }\end{array}$ & $\begin{array}{l}\text { Si :19,6\%; Al:4,9\%; K: 4,0\%; Na: 2,4\%; Ca: } \\
\text { 0,7\%; C: 25,7\% e O: 42,2\% }\end{array}$ \\
\hline W3D MASTER & $\begin{array}{l}\text { Wilcos do Brasil Ind. e Com. } \\
\text { Ltda., RJ, Brazil }\end{array}$ & $\begin{array}{l}\text { Methacrylate monomers, pyrogenic silica, } \\
\text { barium and aluminum silicate }\end{array}$ \\
\hline $\mathbf{1 0 \%}$ hydrofluoric acid & Dentsply, Petrópolis, RJ, Brazil & Hydrofluoric acid, water, thickener and dye \\
\hline Porcelain Primer & Bisco, Schaumburg, IL, USA & $\begin{array}{l}\text { hydrolyzed y-methacryloxypropyl trimethoxy } \\
\text { silane }\end{array}$ \\
\hline RelyX ${ }^{\text {TM }}$ ARC & $\begin{array}{l}\text { Paste A: Bis-GMA, TEGDMA, particles of } \\
\text { zirconia/silica, photoinitiator, pigments } \\
\text { Paste B: Bis-GMA, TEGDMA, particles of } \\
\text { zirconia/silica, benzoyl peroxide }\end{array}$ \\
\hline
\end{tabular}

Table 2. Experimental design of the study, considering the etching time and ultrasonic cleaning factors $(n=8)$.

\begin{tabular}{l|l|l}
\hline Group & Etching time & Ultrasonic cleaning \\
\hline $\mathbf{1}$ & 20 seconds & \multirow{2}{*}{ Without } \\
$\mathbf{2}$ & 1 minute & \\
$\mathbf{3}$ & 2 minutes & \\
\hline $\mathbf{4}$ & 20 seconds & \multirow{2}{*}{ With } \\
$\mathbf{5}$ & 1 minute & \\
$\mathbf{6}$ & 2 minutes & \\
\hline
\end{tabular}

Table 3. Analysis of variance of bond strength data (MPa).

\begin{tabular}{c|c|c|c|c|c}
\hline Source of variation & df & SS & MS & F & p \\
\hline Ultrasonic cleaning & 1 & 132.00 & 132.00 & 16.66 & $0.001^{*}$ \\
Time of acid etching & 2 & 30.74 & 15.37 & 1.94 & 0.156 \\
Interaction & 2 & 9.71 & 4.86 & 0.61 & 0.547 \\
Residue & 42 & 332.80 & 7.92 & & \\
Total & 47 & 505.25 & & & \\
\hline
\end{tabular}

${ }^{*} p<0.05$ 
Table 4. Mean ( \pm standard deviation) of bond strength data (MPa) for the groups and post-hoc Tukey test (Mean values followed by same letters are not statistically different from each other, at the $5 \%$ level)

\begin{tabular}{c|cc|c}
\hline \multirow{2}{*}{ Etching time } & \multicolumn{2}{|c|}{ Ultrasonic cleaning } & \multirow{2}{*}{ Line } \\
\cline { 2 - 3 } & Without cleaning & With cleaning & \\
\hline $\mathbf{2 0} \mathbf{~ s}$ & $16.2 \pm 3.4^{\mathrm{b}}$ & $19.4 \pm 4.2^{\mathrm{a}}$ & $17.8 \pm 4$ \\
$\mathbf{1}$ min & $14.7 \pm 1.2^{\mathrm{b}}$ & $19.2 \pm 0.8^{\mathrm{a}}$ & $16.9 \pm 2.5$ \\
$\mathbf{2}$ min & $17.7 \pm 3.9^{\mathrm{b}}$ & $20 \pm 1.1^{\mathrm{a}}$ & $18.9 \pm 3$ \\
\hline Column & $16.2 \pm 3.2^{\mathrm{A}}$ & $19.5 \pm 2.5^{\mathrm{B}}$ & \\
\hline
\end{tabular}

